\title{
Model and system simulation of Brushless DC motor based on SVPWM control
}

\author{
Yi Huang ${ }^{1}$, Chunquan $\mathrm{Li}^{2}$ \\ School of mechanical \& Electrical Engineering, Guilin University of Electronic Technology, Guilin \\ Guangxi 541004, China \\ ${ }^{1}$ huangyi116@yahoo.com.cn, ${ }^{2}$ Icq@guet.edu.cn
}

Key words: Blushless DC motor; modeling and simulation; space vector pulse width modulation (SVPWM)

\begin{abstract}
According to the disadvantages as large torque ripple of square wave drive brushless DC motor control system, this paper adopted the sine wave drive the permanent magnet brushless DC motor control system based on the space vector pulse width modulation (SVPWM) control method. The simulation model of space vector pulse width modulation control method of the rotated speed of brushless DC motor and current double closed-loop control system is simulated and analyzed in MATLAB/SIMULINK. The simulation results have verified the reasonability and validity of the simulation model.
\end{abstract}

\section{Introduction}

In recent years, as permanent magnet materials, computer technology, intelligent control technology and power electronics technology, especially the power switch component technology has been rapid development, and it laid an important foundation for the research and manufacture of the permanent magnet brushless DC motor (BLDCM). Because of its small size, easy maintenance, control of high precision, the BLDCM widely used in the field of CNC machine tool, robots, servo control. Most of the traditional control system using a square wave pulse width modulation (PWM) the driver control[1], this driver control is simple structure, easy to implement, but the phase voltage and current are only approximates sine wave as the PWM through the inverter is also square wave, and resulting in larger torque ripple. However, sine wave drive permanent magnet BLDCM[2], the phase voltage and current is more nearly in sine wave can be a good reduce its shortcoming after in the inverter at use SVPWM control[3]. Based on MATLAB software, this study established a simulation model which the speed, current double closed loop control system, and used the classical PI control algorithm, to verify its validity, and comparing the current waveform of the conventional PWM control system.

\section{SVPWM control[4]}

The SVPWM is defined in accordance with the spatial position of the windings applied to the voltage. Three-phase stator phase voltage that applied on the three-phase winding can define three voltage space vector. The direction of space vector is always in various axis, while the size of it changes over time, with pulse sinusoid ally time phase difference of $120^{\circ}$. Three voltage space vector prove that the summing synthesizer space vector is a rotating space vector. Figure 1 shows a schematic diagram of the three-phase PWM inverter powered.

\footnotetext{
${ }^{1}$ Supported by National Natural Science Foundation of China(51165004, 61102012)

${ }^{2}$ Guangxi Natural Science Foundation(2012GXNSFDA053029)
} 


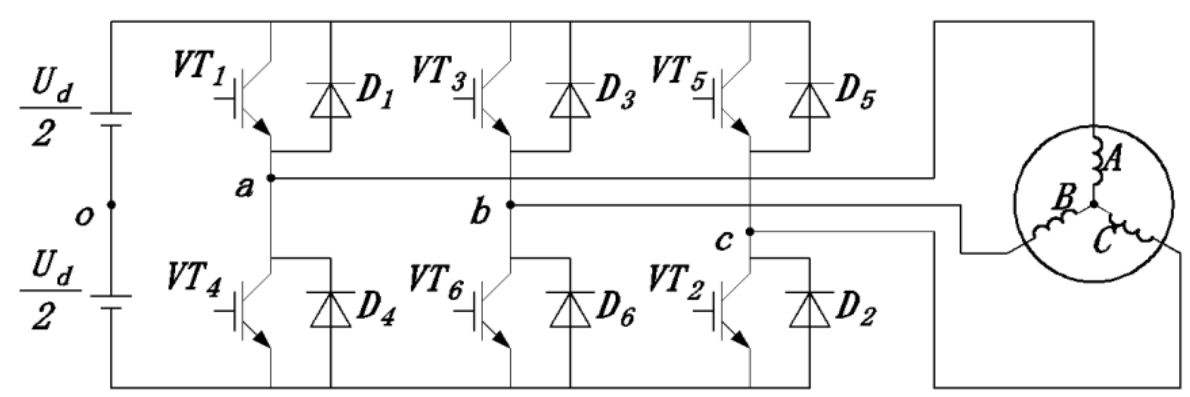

Figure 1 Three-phase PWM inverter power supply principle diagram

$S_{a}, S_{b}, S_{c}$ denote the six amount of A,B,C three-phase switching transistor switch, $S_{a}, S_{b}, S_{c}$ are set to 1 indicates that the corresponding upper arm conduction, opposite each of 0 indicates that the corresponding lower arm conduction. Therefore, there are eight kinds of switch status for the entire three-phase inverter. These eight kinds of switching state corresponding to the three-phase output voltage transformed to the voltage space vector in the $\alpha-\beta$ coordinate system is shown in Figure 2.

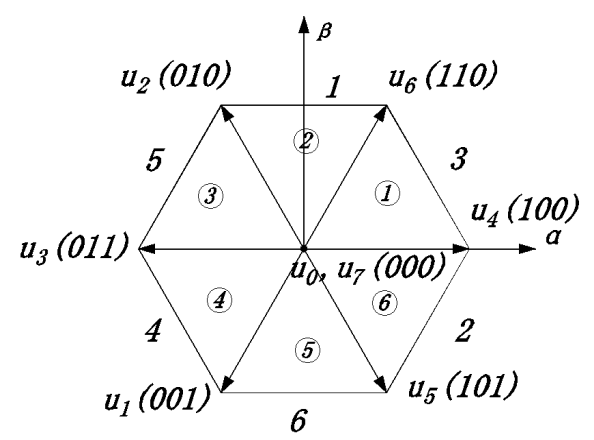

Figure 2 The eight kinds of switching state corresponding to the three-phase output voltage transformed to the voltage space vector in the $\alpha-\beta$ coordinate system

If the inverter is switched every $60^{\circ}$ electrical angle for once the switching state in accordance with the clockwise rotation, one cycle switch six times, the same-phase upper and lower arm are turned on each other $180^{\circ}$ [5]. Mutual $120^{\circ}$ Hall sensor just have six switched from position signal, there will be one of Hall signal phase flip as the rotor rotation $60^{\circ}$ point angle, so just in the position signal flip moment switched voltage space vector controlled operation will be able to achieve its conduction mode.

\section{BLDCM control system simulation model}

The BLDCM control system has dual closed-loop control that the outer speed loop and inner current loop, and uses classic PI control algorithm. The overall system block diagram is shown in Figure 3.

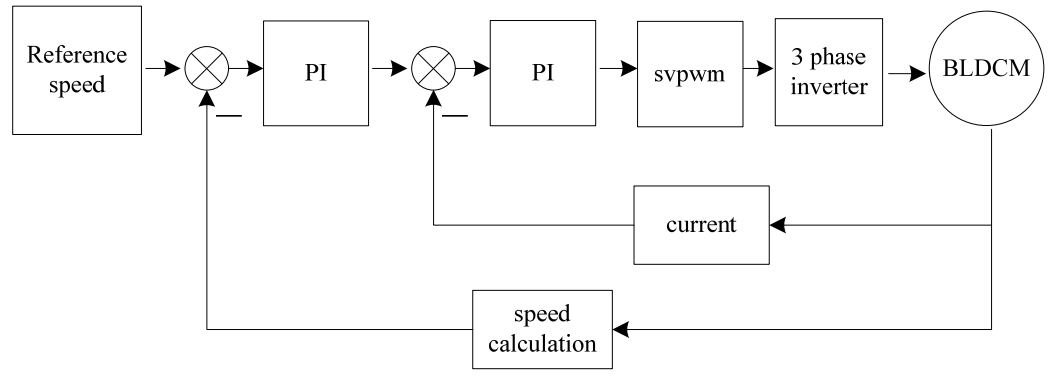

Figure 3 The overall system block diagram of BLDCM control system

In the current closed loop, three-phase current are converted to the system rotating coordinate current by the coordinate transformation of the electrical system analysis[6,7] formula as(1)(2), for the feedback current. 


$$
\begin{aligned}
& \left(\begin{array}{l}
i_{\alpha} \\
i_{\beta}
\end{array}\right)=\sqrt{\frac{2}{3}}\left(\begin{array}{ccc}
1 & -\frac{1}{2} & -\frac{1}{2} \\
0 & \frac{\sqrt{3}}{2} & -\frac{\sqrt{3}}{2}
\end{array}\right)\left(\begin{array}{l}
i_{A} \\
i_{B} \\
i_{C}
\end{array}\right) \\
& \left(\begin{array}{l}
i_{d} \\
i_{q}
\end{array}\right)=\left(\begin{array}{cc}
\cos \theta & \sin \theta \\
-\sin \theta & \cos \theta
\end{array}\right)\left(\begin{array}{l}
i_{\alpha} \\
i_{\beta}
\end{array}\right)
\end{aligned}
$$

Where $i_{\alpha}, i_{\beta}$ are $\alpha-\beta$ coordinate component, ${ }^{i} A,{ }_{B}{ }^{i} C$ are phase A、B、C current, $i_{d}, i_{q}$ are d-q coordinate component, $\theta$ is the axis of the rotor and the stator A phase winding axis angle. Rotor position is determined by motor rotation at the whole simulation system. System inverter module is build by the SVPWM control principle and control algorithm. BLDCM uses Permanent Magnet Synchronous Machine motor module from SIMULINK/SIMPOWER SYSTEMS. The counter electromotive force chooses sine waveform. Inverter chooses general inverter bridge of MOSFET device. To establish system model is shown in Figure 4.

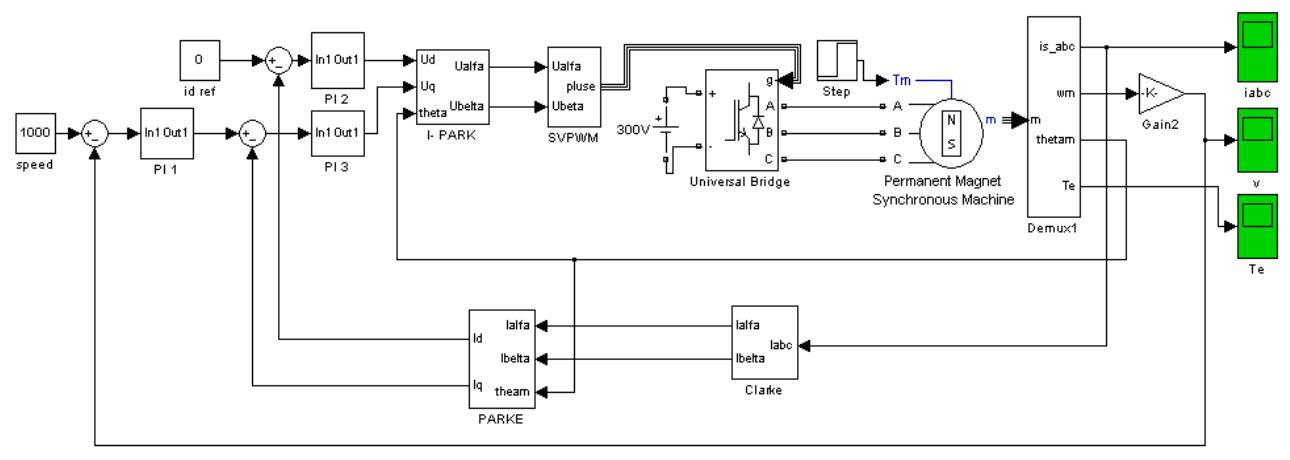

Figure 4 System simulation model

\section{The simulation results}

In order to verify the reliability of the simulation system, Simulation analysis selecting motor pole logarithmic $\mathrm{P}=4, \mathrm{R}=2.875(\Omega), L_{d}=L_{q}=0.00525(\mathrm{H}), \mathrm{J}=6.329 \mathrm{e}-4\left(\mathrm{~kg} \cdot \mathrm{m}^{2}\right), \mathrm{B}=0.1827(\mathrm{~Wb})$, power $\mathrm{DC}=300(\mathrm{~V})$, Reference speeds $\mathrm{n}=1000(\mathrm{RPM})$. The simulation time is $0.3 \mathrm{~s}$, no-load starting, plus load torque $T_{L}=3 \mathrm{~N} \cdot \mathrm{m}$ at $0.1 \mathrm{~s}$. The output waveform is shown in Figure 5-7.

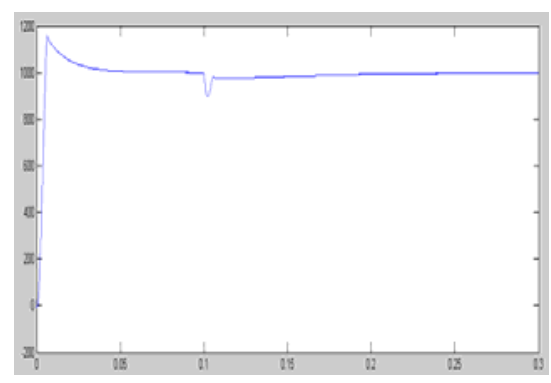

Figure 5 Speed information

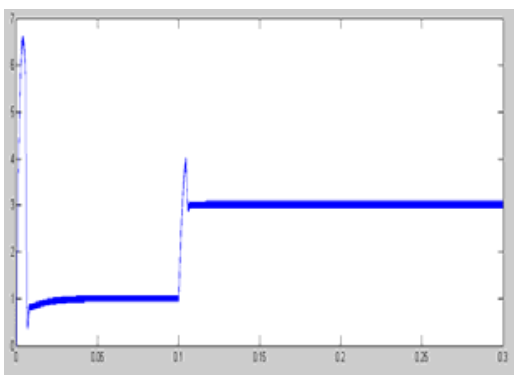

Figure 6 Torque waveform

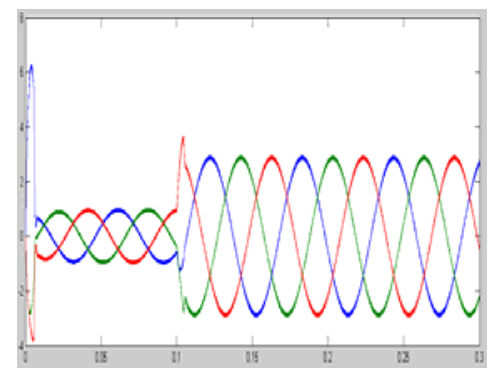

Figure 7 The motor stator three-phase current waveform

In the same motor parameters and simulation parameter settings, using PWM and SVPWM control get a current waveform of A phase as shown in Figure 8, so as to prove the SVPWM control of phase current closer sine wave. 


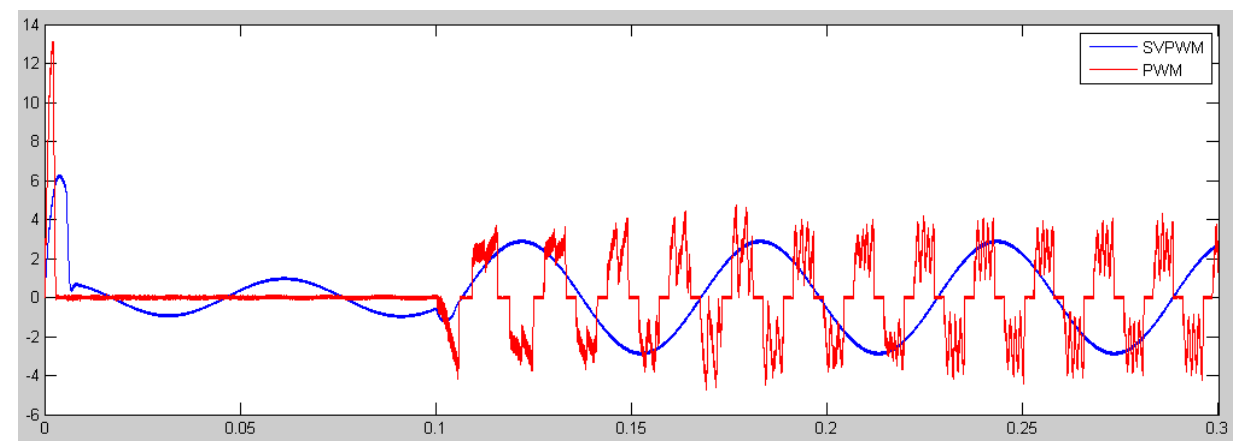

Figure 8 Phase A current use PWM and SVPWM control

\section{Conclusion}

In this paper, the SVPWM control of BLDCM simulation model is established based on the MATLAB/SIMULINK, and used the classic speed, current double closed-loop PI control algorithm. From the output waveform, it can be seen the system corresponding speed fast, quickly achieve steady state. Plus load torque at $\mathrm{t}=0.1 \mathrm{~s}$, the speed happen fell but return to equilibrium state at soon. Three phase stator current waveform as nearly as sine wave. The simulation results show that the SVPWM control of BLDCM has good static and dynamic characteristics.

\section{References}

[1]Wu Quan-li, Huang Hong-quan. Simulation study of penmanent maagnet brushless DC motor based on PWM control. Electrical switches, Vol.5 (2010), p. 39-41

[2]Ma Ruiqing, Deng Junjun. Research on characteristic of sinusoidal current driving method for BLDCM with hall position sensor. Micro-motor, Vol.7 (2011), p. 59-61

[3]Wang Shuhong. A control strategy of PMDC brushless motor based on SVPWM. Automation Expo, Vol.10 (2008), p. 66-68

[4]Qiu Jianqi. SVPWM control for torque ripple attenuation of PM brushless DC motors. Small and medium-sized motor. Vol.2 (2003), p. 27-28

[5]Boyang Hu.180-Degree Commutation System of Permanent Magnet Brushless DC Motor Drive Based on Speed and Current Control.2009 Sencond International Conference on Intelligent Computation Technology and Automation, Vol.2 (2009), p. 723-726

[6]Xia Changliang. Brushless DC motor control system. Beijing: Science Press, (2009)

[7]Hong Naigang. Modeling and simulation of power electronics, motor control system. Beijing: Machinery Industry Press, (2010) 